\title{
Applying the Verifiability Approach in an International Airport Setting
}

\author{
Louise M Jupe* \\ Sharon Leal \\ Aldert Vrij \\ Department of Psychology, University of Portsmouth, UK \\ Galit Nahari \\ Department of Criminology. Bar-Ilan University, Israel
}

*Address for correspondence: Louise Jupe, Department of Psychology, University of Portsmouth, King Henry Building, King Henry I Street, Portsmouth, PO1 2DY. UK. louise.jupe@port.ac.uk. T: +44 239284661 


\begin{abstract}
In the current study we tested the utility of applying the Verifiability Approach within an International airport setting. The Verifiability Approach works on the notion that truth tellers provide more verifiable details than liars and has shown to be successful within other empirical deception detection scenarios. 399 airside participants (those originating from Europe, Asia and African) were asked questions regarding their travel plans. We asked participants to either lie $(n=195)$ or tell the truth $(n=204)$ about their planned activities. The critical question required participants to provide information that would convince the investigator they were telling the truth. We then transcribed and coded their responses for verifiable details; that is details that could potentially be checked by an investigator. Overall, truth tellers provided significantly more verifiable details than liars. Furthermore, when taking their geographical origin into account, there was no interaction effect between veracity and region. Additionally, truth tellers provided a higher verifiable/total detail ratio than liars, which again showed no interaction effect between veracity and region. These findings support the suitability of the Verifiability Approach as a cross-cultural veracity tool and implications for its use as an additional security aid are discussed.
\end{abstract}

Keywords: deception, cross-cultural lie detection, verifiability approach, verbal cues, airport security 


\section{Applying the Verifiability Approach in an International Airport Setting}

Airport Security is based upon the assessment of human behaviours within a set of basic rule breaking parameters (Kirschenbaum, 2015). That is, specific behavioural triggers which appear different to normal in-group behaviours are likely to flag individuals as 'suspicious' to security personnel. When assessing deceptive behaviour within an international setting such as an airport, cultural differences are likely to negatively affect veracity judgments (Taylor, Larner, Conchie \& Van der Zee, 2014). For the purpose of this study, we have collated individuals from specific regions into groups and define a crosscultural interaction as one where the parties involved are generally from different countries, who speak different native languages and predominately reside in different geographical locations. Region and culture are used interchangeably in this paper. Whilst specific definitions relating to culture differ from domain to domain and often researcher to researcher, we refer to culture as specific societal groups in which different objective variables are noted such as the frequencies of specific traits, commonly held beliefs and cultural customs (Ember \& Ember, 1998; Bochner, 2015). Whilst no society or ethic group are entirely homogenous (Bochner, 1982), individuals who identity as originating from specific regions in the current paper, are objectively termed as belonging to the same culture. That is, groups who share a way of life (Berry, 2002).

Airport security agents often use techniques that are not built upon scientific findings. For example, the Screening Passengers by Observation Techniques (SPOT), initially implemented in the US by the Transportation Security Administration, facilitated the use of Behaviour Detection Officers (BDO's) to identify high-risk individuals on overt behaviour (Maccario, 2013), including that of facial micro-expressions and body language (Meyer, 2010). Despite the fact that there is no evidence to suggest that observers can detect micro-expressions in real-time (Honts, Hartwig, Kleinman, \& Meissner, 2009) and that, 
instead, paying attention to non-verbal behaviour leads to poor accuracy (see Bond \& DePaulo, 2006), SPOT was implemented in 161 US airports, costing the US approximately \$200 million annually (Perry \& Gilbey, 2011). The Government Accountability Office (2013) concluded that there was a lack of scientific evidence to support SPOT in its current form and suggested the reduction of its funding. A further example of systems in place to detect deception within airport settings with little scientific support is that of voice stress analysis. The Nemesysco Company state that Moscow Airport used their deception section voice analysis software Gate Keeper (Eriksson \& Lacerda, 2007). However, meta-analysis by Giddens, Barron, Byrd-Craven, Clark, \& Winter, (2013) concluded that findings from voice stress analysis are unequivocal and idiosyncratic. In addition, further research demonstrates that voice stress analysis deception detection success operates at approximately chance level (Harnsberger \& Hollien, 2016).

A factor that hampers lie detection is common misperceptions individuals hold about lying. Such misperceptions are often based upon anxiety based protocols; the notion that liars feel increased levels of guilt, shame and anxiety which can be objectively observed, without full appreciation of the anxiety and stress many truth tellers feel when interviewed or falsely accused (Bond \& Fahey, 1987). Such misconceptions appear to be mirrored worldwide with The Global Research Team (2006) identifying that $65 \%$ of respondents from 75 countries listed cues such as gaze aversion as a signifier of deception, along with incoherence and nervousness, which are no more than weakly correlated (DePaulo et al., 2003).

The respective merits of verbal versus non-verbal cues to deception is a contentious issue within contemporary deception literature. From the initial theoretical underpinnings of the association between internal states (emotion) and objectively identifiable behaviours (Darwin, 1872), non-verbal cues to deception were initially deemed the most diagnostic and potentially useful when assessing the veracity of an individual's statement (Ekman \& 
O'Sullivan, 1991; Ekman, O'Sullivan \& Frank, 1999). However, in their seminal paper, DePaulo et al., (2003) demonstrated that many previously assumed diagnostic non-verbal cues to deception were often weak and unreliable. In addition, the US National Research Council (2003) were unequivocal in their position, that there is no theoretical justification as to why psychological states of emotion would be significantly different between truth tellers and liars.

DePaulo et al.'s (2003) meta-analysis of 120 samples, investigating 158 assumed cues to deception, was able to show that those with the most diagnostic value were more related to the linguistic components of the stories that were told than to the behaviours which were observed, with liars' stories appearing less forthcoming, less compelling, including fewer ordinary imperfections and unusual contents. The difference between nonverbal and verbal cues to deception is that verbal cues predominantly stem from cognitive processes (Schriefers \& Vigliocco, 2015); that is there is a conscious and deliberate mental process, which precedes the production of verbal responses. That is, speech is not autonomous and individuals must think about their specific responses. Such verbal responses may demonstrate partial introspective access to mental processes which are otherwise immeasurable (Nisbett \& Wilson, 1977), although this assumption is at times debatable (Smith \& Miller, 1978). By increasing cognitive load - a technique used based upon the premises that lying is more cognitively demanding telling the truth (Vrij, Fisher, Mann \& Leal, 2008; Blandón-Gitlin, Fenn, Masip \& Yoo, 2014) - the internal dual narrative required by liars (lying while remembering the truth; Jupe, Vrij, Nahari, Leal \& Mann, 2016) creates a more complex task and therefore, theoretically, should increase the difficulty of producing a statement which echoes those of truth tellers. It is these difficulties which allow for an increase in the diagnosticity of verbal cues. The Strategic Use of Evidence (SUE) approach (Hartwig, Granhag, Strömwall \& Kronkvist, 2006) demonstrated that verbal cues to deception such as 
evidence-related information and statement-evidence inconsistencies are generated from specific questioning techniques which result in varying verbal responses between truth tellers and liars, such as avoidance and denial (Hartwig, Granhag \& Luke, 2014).

Airport security is challenging, not only due to the high numbers of individuals who pass through daily, but due to the vast array of different cultures from which these individuals originate. With such a diverse assembly of individuals, potential cultural differences are likely to affect judgements and decisions by members of airport security. One of the underlying difficulties in making cross-cultural veracity judgments is that humans are aligned to specific cultural norms, that is behaviour which an individual believes their culture would view as appropriate (Heinrichs, Rapee, Alden, Bögels, Hofmann \& Sakano, 2006). When an individual has to make a behavioural analysis outside of his or her own in-group norms, such divergent properties affect the way in which the behaviour is understood. That is, individuals making veracity judgments need to be able to view others through the lens of the particular individuals own specific culture and that due to such complexities, the ability to detect deception deteriorates when assessments are made cross-culturally (Taylor, Larner, Conchie \& Van der Zee, 2014; Bond, Omar, Mahmoud \& Bonse, 1990; Global Deception Research Team, 2006). This in known as a norm violation model of veracity judgements (Levine et al., 2000). Because unexpected behaviours are deemed as less honest, this in turn affects veracity judgements.

In addition to cross-cultural complexities and a lack of understanding surrounding actual deceptive behaviour, aviation security is restricted by scarce resources (Poole, 2015). Therefore, detection methods that are scientifically driven, financially viable, and can be used cross-culturally need to become available. The current study looks at the applicability of a verbal veracity tool, the Verifiability Approach (VA), when applied cross-culturally within an airport setting. 


\section{The Verifiability Approach}

Analysis of speech content has shown promise within deception detection, with Statement Validity Analysis the most frequently used method to date (Vrij, 2008, 2015). Recent research has shown that when applied to cross-cultural written statements, SVA is a significant predictor of veracity (Matsumoto, Hwang \& Sandoval, 2015), that is that by using SVA, the veracity of a significant number of statements are classified correctly. Language did not appear to be a moderator, suggesting cross-cultural similarity within SVA indicators across the statements. However, SVA is time-consuming to carry out and therefore not a viable method in an airport setting.

The Verifiability Approach (VA), a verbal veracity tool introduced by Nahari, Vrij and Fisher (2014a), is built upon two research based assumptions. First, liars prefer to provide lots of details because they are aware that accounts rich in detail are more likely to be believed (Bell \& Loftus, 1989). Second, liars prefer to avoid mentioning too many details out of fear that investigators will check such details (Nahari, Vrij, \& Fisher, 2012). A strategy that compromises both motivations is to provide details that cannot be verified. Liars use this strategy and are more likely to provide details which cannot be checked (e.g., 'I saw a young girl cross over to Turk Street') over those which can be checked (e.g., 'I sent an email to accounts at 3pm yesterday afternoon') (Nahari et al., 2014a, Nahari, Vrij and Fisher, 2014b; Nahari \& Vrij, 2014b, 2015; Nahari, Leal, Vrij, Warmelink \& Vernham, 2014; Harvey, Vrij, Nahari \& Ludwig, 2016). The current research into the VA is promising. It has been successfully applied to three settings thus far including criminal (e.g., Nahari et al, 2014a, 2014b; Nahari \& Vrij, 2014; Vernham, Vrij, Leal, Mann \& Nahari, 2017, Jupe, Vrij, Leal, Nahari \& Harvey, 2017), insurance (Nahari, Leal et al., 2014, Vrij , Nahari, Isitt \& Leal, 2016; Harvey et al., 2016) and malingering (Boscovic, Boogaard, Merckelbach, Vrij \& Hope, 2017; Boscovic, Tejada-Gallardo, Merckelbach, Vrij \& Hope, 2017). The first study by 
Nahari, Vrij and Fisher (2014a), asked truth tellers to report their true activities for the previous 30 minutes, whilst liars were asked to lie about their previous activities. When the VA was applied to their transcribed statements, that is, coded for all occurrences of verifiable details, it was accurately able to distinguish between the veracity of $78.9 \%$ of statements.

The first VA study did not specifically inform participants that the interviewer would be looking for the provision of verifiable detail prior to interview. In the initial study, statements were checked for the occurrence of spontaneous verifiable detail (Nahari, Vrij et al., 2014a). However, the findings from this research encouraged the use of specifically asking participants to provide verifiable detail, known as the 'information protocol' (Nahari et al., 2014b). An additional study which did not explicitly inform participants of the requirement to check for verifiable detail did not show as promising results (Jupe, Vrij, Nahari, Leal \& Mann, 2016). However, the explicit request for verifiable detail has shown better discrimination between truth tellers and liars (Nahari, Vrij et al., 2014b; Nahari \& Vrij, 2014b, 2015; Harvey et al., 2016). The difference in reporting verifiable detail between truth tellers and liars is typically larger in the second method than in the first method as awareness that the investigator is interested in verifiable details makes truth tellers more than liars to provide such details.

In the current study, rather than paying attention to the number of verifiable detail interviewees provide, the investigator asked an interviewee at the end of the interview what information the interviewee can give that reassures the investigator that the interviewee was telling the truth during the interview. Differences may be seen between truth tellers and liars in the amount of verifiability of these reassurances. Based on the Verifiability Approach we predict that truth tellers will provide significantly more reassurances that can be verified than liars (Hypothesis 1). 
Research indicates that cultural differences exist in nonverbal behaviour (e.g., Cheng \& Broadhurst, 2005), speech (Wierzbicka, 1985; Samovar, Porter, McDaniel \& Roy, 2015; Taylor et al., 2015), basic human values (Schwartz, Melech, Lehmann, Burgess, Harris \& Owens, 2001) and facial expression (Russell, 1994). Research into linguistic components across ethnicities seems to show the diagnostic value remains stable; that is, linguistic markers are able to differentiate liars from truth tellers across ethnicities. Research by Matsumoto, Hwang and Sandoval, (2015) has shown that ethnicity is not a mediator for veracity when related to some linguistic components; that is some linguistic markers of deception were able to distinguish truths from lies across a variation of cultures and backgrounds. In addition, verifiable details are generally assumed to be dichotomous (we can either verify something, or we cannot). Since, by definition, an airport is a cross-cultural setting we cannot think of a theoretical reason as to why this effect would be regionally dependent; i.e., why the verifiability of details (or those provided) would vary depending on the region from which an individual originates and thus we predict that the verifiable details effect will remain stable across different regional groups. We also predict that the ratio of verifiable/total details will be higher for truth tellers than for liars (Hypothesis 2).

\section{Method}

The current study explores the usefulness of the VA as a verbal veracity tool, within an airport setting. Individuals in an airport departure lounge were asked to lie or tell the truth about their forthcoming trip. Specifically, individuals were asked for information that they could provide which would reassure the interviewer that they were telling the truth about their trip. In addition, three regional groups were examined: Europe, Asia and Africa. The aim was to be able to differentiate between truth tellers and liars based on the verifiable information they provide and if the findings are applicable in a cross-cultural setting.

\section{Participants}


Data for the current study was extracted from raw data provided by the study for Vrij, Granhag, Mann and Leal (2011). A total of 399 participants took part in the study, comprising of 270 males and 117 females (gender information for 12 participants was missing). They were aged between 16 and 75 years of age $(M=35.05, S D=12.71) .160$ of the participants were classified as originating from Europe, 160 from Asia and 80 from Africa. Participants were classified by their responses to questions regarding their regional origin. Participants were presented with a selection of the following: Western Europe, Southern Europe, Eastern Europe, Russian, South Asia, East Asia, South East Asia, West Asian, West African or East Africa. These 10 regional groups were then further identified by the researchers as Europe (Western Europe, Southern Europe, Eastern Europe, Russia), Asia (South Asia, East Asia, South East Asia, West Asian) or Africa (West Africa, East Africa) in terms of their geographical location.

\section{Procedure}

The location for the study was an international airport and used airside passengers as participants. Airside passengers are those who have access to the aircraft (post security) as opposed to landside passengers (those who have yet to pass through security). The experimenter approached airside passengers on an opportunity sampling basis and asked: 'I am from the Psychology Department of the University of Portsmouth and would like to ask you some questions about your travel plans for a study about memory'.

The participants that agreed were asked where it was that they were flying to and the purpose of their trip. The experimenter made a note of the answers. Some of the passengers were returning home and others travelling away on a trip. Those that were returning home were thanked for their time. Those that were going away on a trip were then asked the following: 
'Are you willing to participate in a study that involves telling a convincing story about your travel plans with the chance of earning $£ 10$ ? The interview will be video and audiotaped. My colleague will ask you some questions about your forthcoming trip. Some people will be asked to tell the truth whereas others will be asked to lie during these interviews. My colleague, who does not know who is lying or telling the truth, will make a veracity judgment at the end of the interview. When my colleague believes that you are telling the truth, you will get $£ 10$, if she thinks that you are lying, you may not get any money. [In fact, all participants received £10, see below.] Do you understand the procedure? Are you willing to participate?'

The majority of individuals agreed to participate. For those that did not, their reasons were deemed reasonable, such as they were already running late or had to work. Participants were randomly assigned to either a truth telling $(n=204)$ or lying $(n=195)$ condition (using a block randomisation method which a block size of four for each of the ten Regions). Truth tellers were asked to answer the interviewer truthfully, whereas liars were told to lie about the purpose of their trip, whilst remaining truthful about the destination. The participants were asked if they needed any preparation time and if they did, were allowed as much time as they required. After, the participants were taken to one of two female interviewers, blind to their veracity status, who introduced themselves and then turned on the video and audio recorders. The interviewer asked the participants about where they were flying to and the purpose of their trip. Before the end of the interview, the interviewer asked the following question, relevant for the current study:

'Is there any information you can give me that reassures me that you are telling the truth about the purpose of your trip?' 
After the interview, the interviewer stated if she thought they were lying or telling the truth and gave all participants $£ 10$ for their participation, irrespective of her decision. The participants were debriefed and given a debriefing form.

\section{Coding}

The audio recordings of the interviews were transcribed. A coder, blind to the veracity of the statements, organised and quantified the responses to the question 'Is there any information you can give me that reassures me that you are telling the truth about the purpose of your trip?', into the following: (1) total information provided, and (2) if that information was potentially verifiable. Total information provided related to the total number of individual pieces of detail provided by the interviewee, irrespective of their relevance or verifiability. For example, "I am travelling to Spain to meet my business partner. We are going to meet at the Oliovio Restaurant in Seville" is the equivalent of two pieces of information. As the questions asked for information that could reassure the investigator, the two pieces of information here are: 'I am travelling to Spain to meet my business partner' and 'We are going to meet at the Oliovio Restaurant in Seville'. Within Reality Monitoring (RM) coding we may break this down into more specific pieces but due to the time constraints placed upon aviation security agents, collating this into two pieces of information is be deemed more suitable for the setting it is to be applied within. Verifiable information is that which is potentially verifiable by an investigator. For definition, verifiable information refers to activities that are: i) carried out with or ii) witnessed by named persons or persons who can be identified based on the description given; iii) Activities that the interviewee believes may have been captured on CCTV; iv) activities that were documented or recorded other than CCTV (such as, using debit cards, mobile phones, or computers, noting attendance on a class register). In the current study, we look for information which an investigator could check, if required, with regards to future activities relating to their trip. For example, "I am attending 
the Biennial Conference on Chemical Education in Singapore" is verifiable (we can check their conference registration) whilst "I am going to visit some different shops in Verona to look for a dress" in unverifiable information; that is we have no tangible way of confirming if this is in fact true.

\section{Inter-rater reliability.}

A second coder, also blind to the veracity status of the interviews, coded 100 of the $399(25.06 \%)$ interviews for information was potentially verifiable. The inter-rater reliability score was high: potentially verifiable information $[\mathrm{ICC}]=.968$.

\section{Results}

The data were analysed with two, two-factor between-subjects ANOVAs with Veracity (truth teller vs liar) and Region (Europe vs Asia vs Africa) as the between-subjects variables and total number of verifiable details and verifiable details/total details ratio as the dependent variables. The ANOVA for total number of verifiable details revealed a significant main effect for Veracity, with truth tellers providing more verifiable detail $(M=.78, S D=$ 1.22) than liars $(M=.48, S D=.92), F(1,393)=6.76, p=.010, \eta^{2}=.02, d=0.28$, supporting Hypothesis 1 . The main effect for Region was not significant (Africa $(M=.50, S D=.86)$, Asia $(M=.57, S D=.94)$ and Europe $(M=.78, S D=1.31), F(2,393)=2.08, p=.127, \eta^{2}=$ $.01)$. There was not a significant Veracity X Region interaction effect, $F(6,784)=2.00, p=$ $.063, \eta^{2}=.00$ (see Table 1 for descriptive statistics).

Regarding the verifiable detail/total detail ratio, a significant main effect was found for Veracity with truth tellers having a higher ratio $(M=.24, S D=.34)$ than liars $(M=.18$, $S D=.32), F(1,379)=3.42, p=.032, \eta^{2}=.01, d=.18$. This supports Hypothesis 2 . There was no significant main effect for Region (Africa $(M=.15, S D=.28)$, Asia $(M=.21, S D=$ $.34)$ and Europe $\left.(M=.24, S D=.34), F(2,379)=1.48, p=.239, \eta^{2}=.01\right)$. The Veracity $\mathrm{X}$ 
Region interaction was not significant $F(2,379)=.887, p=.413, \eta^{2}=.00$ (see Table 1 for descriptive statistics).

\section{Discussion}

In the current study, a new approach to discriminate between truth tellers and liars, the Verifiability Approach, was utilised in an airport setting, to examine its applicability within cross-cultural security settings. As per previous findings (e.g., Nahari, Vrij et al., 2014a; Nahari, Vrij et al., 2014b; Nahari, Leal et al., 2014), the VA was able to discriminate between truth tellers and liars on the basis of the amount of verifiable detail provided. Such findings add further support to the use of the VA as a verbal veracity tool. In addition, when examined from a cross-cultural perspective, the VA was not mediated by region. Whilst there were differences in total detail provided between individuals from Europe, Asia and Africa, when examining the critical variable, verifiable detail, no main effects were found.

Furthermore, when verifiable detail was looked at in terms of the verifiable/total detail ratio, significant differences were observed between truth tellers and liars, with truth tellers providing a higher ratio of verifiable to total detail. This effect was not mediated by region. This lends support to the use of the VA as a within-subjects veracity tool (the ratio variable is a within-subjects variable), which is preferred amongst practitioners (Warmelink et al., 2012) as it is less likely to be affected by individual differences. This suggests that both truth tellers and liar's statements appear to be affected equally by the application of the VA, irrespective of regional origin. This may be indicative of the suitability of the VA across a variety of cultural settings.

Whilst the findings may only show objectively small differences between truth tellers and liars, it is possible that through strategic approaches, this difference may be magnified. One method of magnification would be to amend the questioning order such that the critical question is asked first. In the current study, the question under study - 'Is there any 
information you can give me that reassures me that you are telling the truth about the purpose of your trip?' - was asked after an initial set of questions and therefore may have been influenced by the preceding questions. That is, individuals may have been less likely to include information that they felt may have already been covered by previous questions. Introducing this question at the beginning of an interview, may increase the number of pieces of information that truth tellers provide, exasperating the diagnostic value of the approach.

An additional method would be to further analyse responses for verifiable details. The current study looks at if the information they offer is verifiable, but in addition there is potential to amend the questioning to allow for investigators to adopt the full VA approach (Nahari, Vrij \& Fisher, 2014a, 2014b). This would potentially allow questions which elicit detailed answers to be provided which can be analysed for verifiable details. This method of magnification can be further enhanced by using an information protocol (IP) (Nahari et al., 2014b; Harvey et al., 2016). An IP in this instance, would be a proactive encouragement of the provision of verifiable details such that individuals would be aware that those are the specific details that an investigator is looking for. This would, in essence, encourage truth tellers to provide more verifiable details whilst causing a dilemma for liars. The use of an IP in other VA studies has shown to be promising (Nahari et al., 2014b; Harvey et al., 2016; Vrij, Nahari, Isitt, \& Leal, 2016). Therefore, it is reasonable to expect that in future studies, if the current study were to be repeated based upon the same methodological processes, yet with the inclusion of the IP, it is likely to further magnitude the differences between truth tellers and liars.

One of the predominant issues when making cross-cultural veracity judgments - that is when the individual being judged and the individual making the judgment are from different regional backgrounds - relates to biases in judgements. Such judgments are often due to cultural norms, which are the normal behavioural pattern one associated with their 
own ethnicity or culture. When making judgements based on behaviour, decision makers often compare the individual under observation to their own behaviour (Taylor et al., 2014). When behaviours displayed by members of other cultures seem unexpected or odd, these members are more likely to be judged as suspicious. This may be due to awkwardness or anxiety felt when facing communicative obstacles (Taylor et al., 2014). The difference with the VA is that it is not a tool to assess overt behaviour, but instead looks at verifiable detail relating to previous or planned behaviours. Whilst behaviour between regions may differ in terms of observers' interpretation of veracity (diverse cultural behaviours may be viewed differently in terms of credibility in terms of a subjective assessment), the information they provide is generally dichotomous (it is either verifiable or it is not). This verifiability of details can be viewed both subjectively (an initial scanning of a statement may provide an investigator with a sense of the level of verifiability) and also objectively (information can be checked and verified through various systems). The subjective analysis can be used, in essence, as a potential screening method before additional - and more time consuminginvestigation is carried out. Truth tellers should naturally have more details which can be verified, no matter their language or culture. Therefore, it seems a reasonable justification that the verifiability of details should not differentiate between cultures, unlike assumed overt assumptions of deceptive 'behaviour'.

Airports security has two basic approaches: uniform screening and selective screening (McLay, Lee \& Jacobson, 2010). Uniform screening is where each passenger is subject to identical screening methods (e.g., mandatory baggage checks). Selective screening identifies passengers who present a higher risk than others in an initial phase, allowing for more thorough checks and interrogation in a secondary phase. Whilst the VA is difficult to apply in phase one, it may be beneficial when slotted into phase two of identification and interrogation of suspicious travellers. 
One may argue that with practice, liars may be able to embed their lies by using verifiable detail obtained from previous experience (Leins, Fisher and Ross, 2013). An embedded lie is when a fragment of deception is integrated into an account of truth when a lie is constructed; that is, a liar will report a previously experienced event in place of the deceptive event or time period. For example, when asked their whereabouts on a previous evening, a liar may be able to describe, in detail, his activities from a different evening altogether. The embedded lie is the 'date' of the activities, whilst the actual activities carried out remains truthful. Leins, Fisher and Ross (2013) found that $67 \%$ of liars will report a previously experienced event when constructing their lies. However, in the current study, the detail which was asked for relates to the specific trip the passengers were taking. Providing verifiable detail in this scenario is more difficult in terms of embedding, as much of the detail provided would need to have tangible proof (hotel reservations, excursion bookings, contact names and numbers of holiday reps etc.). A liar would need to have prepared significantly to be able to provide embedded verifiable details for a trip that he or she is about to take (i.e., booking excursions that he or she does not actually intend to partake in or booking reservations at a hotel which he or she does not intend to stay at). This is supported by the VA countermeasures approach by Nahari et al., (2014b) by where the information protocol enhanced the verifiable detail provided by truth tellers but not liars and additionally by Nahari and Vrij, (2015) in which liars had difficulty embedding lies (providing verifiable detail) into 'innocent' scenarios. Unlike behavioural norms, such data is not open to interpretation - due to its dichotomous nature - and thus intrinsically provides a more viable initial assessment tool than those based on human behaviour. The VA may provide aviation security agents with an additional tool to implement when making important cross-cultural veracity judgements. 
The study is not without limitations. When the experimental paradigm is taken into consideration (that is considering that all participants were aware of their involvement in an experiment) participants may have been unlikely to think that the experimenters would actually check the verifiability of the information provided (i.e., confirm what they have said is true), especially as the participants were not specifically asked to provide verifiable detail. This means that it may have the potential if applied, with explicit instruction in vivo, to actually increase the discriminative ability by encouraging truth tellers to provide more verifiable detail, yet making it increasingly difficult for liars.

In terms of cross-cultural issues, factors need to be considered when making overall assessments of findings relating to cross-cultural veracity decisions. Such aspects include those who present themselves in terms of societal expectations rather than their true selves (Sarabi, 1975), individual beliefs, including stereotypes, regarding deceptive behaviour (The Global Deception Team, 2006) and the detection of deception in either a first or second language (Cheng \& Broadhurst, 2005).

As the current study was springboard research into the applicability of the Verifiability Approach within an applied airport setting, future studies which further explore the possibility of applying the VA, in vivo, are recommended. The discriminative ability of individuals trained in the Verifiability Approach should be investigated alongside applied studies looking at the usefulness of the VA by airport security agents. In addition, the current research is unable to assess how the VA would perform when individuals withhold information. That is, suspicious individuals may use a tactical approach by providing verifiable details which are associated with genuine intentions, yet withhold other information regarding activities which may be indicative of criminal activity. For example, an individual may indeed make reservations at a specific location and arrange excursions etc., yet without any real intention of partaking in such actions. Further research is needed to see 
how the VA may be able to integrate with other methods which are specifically designed to identify lies related to intentions (Warmelink et al., 2012; Vrij, Leal, Mann \& Granhag, 2011; Sooniste, Granhag, Knieps \& Vrij, 2013).

When looked at alongside the overall poor performance of our ability to detect lies across numerous countries (The Global Research Team, 2006) and the ever increasing importance of the judgements made by airport security agents, the VA offers a potential 'onthe-fly’ veracity tool. This may not only increase successful identification of suspicious individuals, but is less likely to be as exhausting on the scare resources available within aviation security (Poole, 2015). Costs would involve the security agent informing the passenger that they require information that is verifiable and a simple count and assess procedure. This is likely to be more time efficient that other measures, such as real-time CBCA or RM assessments (Nahari, Vrij et al., 2014b). Although additional cross-cultural studies using the VA are needed, it has the potential to provide additional tools for use by aviation security agents. 


\section{References}

Bell, B. E., \& Loftus, E. F. (1989). Trivial persuasion in the courtroom: The power of (a few) minor details. Journal of Personality and Social Psychology, 56, 669-679.

Berry, J. W. (2002). Cross-cultural psychology: Research and applications. Cambridge University Press.

Blandón-Gitlin, I., Fenn, E., Masip, J., \& Yoo, A. H. (2014). Cognitive-load approaches to detect deception: searching for cognitive mechanisms. Trends in cognitive sciences, 18(9), 441-444. doi:10.1016/j.tics.2014.05.004

Bochner, S. (ed.) (1982). Cultures in contact: Studies in cross-cultural interaction. Oxford: Pergamon.

Bond Jr, C. F., Omar, A., Mahmoud, A., \& Bonser, R. N. (1990). Lie detection across cultures. Journal of nonverbal behavior, 14(3), 189-204.

Bond, C. F., \& DePaulo, B. M. (2006). Accuracy of deception judgments. Personality and social psychology Review, 10(3), 214-234. doi:10.1207/s15327957pspr1003_2

Bond, C. F., \& Fahey, W. E. (1987). False suspicion and the misperception of deceit. British Journal of Social Psychology, 26, 41-46. doi:10.1111/j.2044-8309.1987.tb00759.x

Boscovic, I., Boogaard, G., Merckelbach, H., Vrij, A., \& Hope, L. (2017). The verifiability approach to detection of malingered physical symptoms. Psychology, Crime, \& Law. doi.org/10.1080/1068316X.2017.1302585

Boscovic, I., Tejada-Gallardo, G., Merckelbach, H., Vrij, A., \& Hope, L. (2017). Verifiability on the run: An experimental study on the Verifiability Approach to malingered symptoms. Manuscript submitted for publication.

Cheng, K. H. W., \& Broadhurst, R. (2005). The detection of deception: The effects of first and second language on lie detection ability. Psychiatry, Psychology and Law, 12(1), 107-118. doi:10.1375/pplt.2005.12.1.107 
Cohen, J. (1994). The earth is round ( $\mathrm{p}<.05)$. American Psychologist, 49, 997-1003.

Darwin, C. (1872). 1965. The expression of the emotions in man and animals. London, UK: John Marry.

DePaulo, B.M., Lindsay, J.J., Malone, B.E., Muhlenbruck, L., Charlton, K., \& Cooper, H. (2003). Cues to deception. Psychological Bulletin, 129, 74-112. doi:10.1037/00332909.129.1.74

Ekman, P., \& O'Sullivan, M. (1991). Who can catch a liar? American Psychologist, 46(9), 913. doi:10.1037/0003-066X.46.9.913

Ekman, P., O'Sullivan, M., \& Frank, M. G. (1999). A few can catch a liar. Psychological Science, 10(3), 263-266. doi:10.1111/1467-9280.00147

Ember, C. R., \& Ember, M. (1998). Cross-cultural research. In H. R. Bernard (Ed.), Handbook of methods in cultural anthropology (pp. 647 - 687). Walnut Creek, CA7 AltaMira.

Eriksson, A., \& Lacerda, F. (2007). Charlatanry in forensic speech science: A problem to be taken seriously. International Journal of Speech, Language and the Law, 14(2), 169-193.

Giddens, C. L., Barron, K. W., Byrd-Craven, J., Clark, K. F., \& Winter, A. S. (2013). Vocal indices of stress: a review. Journal of Voice, 27(3), 390-e21.

Global Deception Research Team. (2006). A world of lies. Journal of Cross-Cultural Psychology, 37(1), 60-74. doi:10.1177/0022022105282295

Government Accountability Office. (2013). TSA should limit future funding for behavior detection activities (GAO Publication No. 14-159). Washington, D.C.: U.S. Government Printing Office

Harnsberger, J. D., \& Hollien, H. (2016). Assessing Deception by Voice Analysis: Part II: The LVA. Investigative Sciences Journal, 8(1). 
Hartwig, M., Granhag, P. A., \& Luke, T. (2014). Strategic use of evidence during investigative interviews: The state of the science. In D. C. Raskin, C. R. Honts, \& J. C. Kircher (Eds.), Credibility assessment: Scientific research and applications (pp. 1-31). Oxford, UK: Elsevier.

Hartwig, M., Granhag, P. A., Strömwall, L. A., \& Kronkvist, O. (2006). Strategic use of evidence during police interviews: When training to detect deception works. Law and human behavior, 30(5), 603-619. doi:10.1007/s10979-006-9053-9

Harvey, A. C., Vrij, A., Nahari, G., \& Ludwig, K. (2016). Applying the Verifiability Approach to insurance claims settings: Exploring the effect of the information protocol. Legal and Criminological Psychology, n/a-n/a. doi:10.1111/lcrp.12092

Heinrichs, N., Rapee, R. M., Alden, L. A., Bögels, S., Hofmann, S. G., Oh, K. J., \& Sakano, Y. (2006). Cultural differences in perceived social norms and social anxiety. Behaviour research and therapy, 44(8), 1187-1197. doi:10.1016/j.brat.2005.09.006

Honts, C. R., Hartwig, M., Kleinman, S. M., \& Meissner, C. A. (2009). Credibility assessment at portals: Portals committee report. Final Report of the Portals Committee to the Defense Academy for Credibility Assessment.

Jupe, L. M., Vrij, A., Leal, S., Nahari, G., \& Harvey, A. (2017). Fading Lies: Applying the Verifiability Approach after a Period of Delay. Manuscript under preparation.

Jupe, L. M., Vrij, A., Nahari, G., Leal, S., \& Mann, S. A. (2016). The lies we live: Using the verifiability approach to detect lying about occupation. Journal of Articles in Support of the Null Hypothesis.

Kirschenbaum, A. A. (2015). The social foundations of airport security. Journal of Air Transport Management, 48, 34-41. doi:10.1016/j.jairtraman.2015.06.010 
Köhnken, G. (1996). Social psychology and the law. In G. R. Semin \& K. Fiedler (Eds.), Applied Social Psychology (pp. 257-282). London, UK: Sage Publications.

Leins, D., Fisher, R., \& Ross, S. (2013). Exploring liars' strategies for creating deceptive reports. Legal \& Criminological Psychology, 18(1), 141-151. doi:10.1111/j.20448333.2011.02041.x

Levine, T. R., Anders, L. N., Banas, J., Baum, K. L., Endo, K., Hu, A. D., \& Wong, N. C. (2000). Norms, expectations, and deception: A norm violation model of veracity judgments. Communications Monographs, 67(2), 123-137. doi:10.1080/03637750009376500

Matsumoto, D., Hwang, H. C., \& Sandoval, V. A. (2015). Ethnic similarities and differences in linguistic indicators of veracity and lying in a moderately high stakes scenario. Journal of Police and Criminal Psychology, 30(1), 15-26. doi:10.1007/s11896-013-9137-7

McLay, L. A., Lee, A. J., \& Jacobson, S. H. (2010). Risk-based policies for airport security checkpoint screening. Transportation Science, 44(3), 333-349. doi:10.1287/trsc.1090.0308

Maccario, J. (2013). Aviation security and nonverbal behavior. In D. Matsumoto, M. G. Frank, \& H. S. Hwang (Eds.). Nonverbal communication: Science and applications (pp. 147-154). Thousand Oaks, CA: Sage

Maltz, Daniel N. and Borker, Ruth A. 1982. A cultural approach to male-female miscommunication. In Language and Social Identity, ed. by John J. Gumperz, 196-216. Cambridge: Cambridge University Press

Masip, J., \& Herrero, C. (2013). 'What would you say if you were guilty?' Suspects' strategies during a hypothetical behavior analysis interview concerning a serious crime. Applied Cognitive Psychology, 27, 60-70. doi:10.1002/acp.2872 
Matsumoto, D., Hwang, H. C., \& Sandoval, V. A. (2015). Cross-language applicability of linguistic features associated with veracity and deception. Journal of Police and Criminal Psychology, 30(4), 229-241. Doi:10.1007/s11896-014-9155-0

Meyer, D. L. (2010). Spot Program: Hello Racial Profiling, Goodbye Fourth Amendment, The. U. Md. LJ Race, Religion, Gender \& Class, 10, 289.

National Research Council, Committee to Review the Scientific Evidence on the Polygraph. (2003). The polygraph and lie detection. Washington, DC: The National Academies Press.

Nahari, G., Leal, S., Vrij, A., Warmelink, L., \& Vernham, Z. (2014). Did somebody see it? Applying the verifiability approach to insurance claims interviews. Journal of Investigative Psychology and Offender Profiling, 11, 237-243. doi:10.1002/jip.1417.

Nahari, G., \& Vrij, A. (2014a). Are you as good as me at telling a story? Individual differences in interpersonal reality monitoring. Psychology, Crime \& Law, 20(6), 573-583. doi:10.1080/1068316X.2013.793771

Nahari, G., \& Vrij, A. (2014b). Can I borrow your alibi? The applicability of the verifiability approach to the case of an alibi witness. Journal of Applied Research in Memory and Cognition, 3(2), 89-94. doi:10.1016/j.jarmac.2014.04.005

Nahari, G., \& Vrij, A. (2015). Can someone fabricate verifiable details when planning in advance? It all depends on the crime scenario. Psychology, Crime \& Law, 21(10), 987-999. doi:10.1080/1068316X.2015.1077248

Nahari, G., Vrij, A., \& Fisher, R. P. (2012). Does the truth come out in the writing? Scan as a lie detection tool. Law and Human Behavior, 36, 68-76. doi:10.1007/s10979-0119264-6 
Nahari, G., Vrij, A., \& Fisher, R. P. (2014a). Exploiting liars' verbal strategies by examining the verifiability of details. Legal and Criminological Psychology, 19(2), 227-239. doi:10.1111/j.2044-8333.2012.02069.x

Nahari, G., Vrij, A., \& Fisher, R. P. (2014b). The verifiability approach: countermeasures facilitate its ability to discriminate between truths and lies. Applied Cognitive Psychology, 28(1). doi:10.1002/acp.2974

Nisbett, R. E., \& Wilson, T. D. (1977). Telling more than we can know: Verbal reports on mental processes. Psychological review, 84(3), 231. doi:10.1037/0033295X.84.3.231

Perry, M., \& Gilbey, A. (2011). The screening of passengers by observation techniques programme: Analyzing the issues. Aviation Security International, 17, 12-13.

Poole, R. W. (2015). Cost-effective airport security policy. In S. Hakim, G. Albert, \& Y. Shiftan, Y. (eds.), Securing Transportation Systems. John Wiley \& Sons. doi:10.1002/9781119078203.ch11

Porter, S., \& Ten Brinke, L. (2008). Reading between the lies identifying concealed and falsified emotions in universal facial expressions.Psychological Science, 19(5), 508514. doi:10.1111/j.1467-9280.2008.02116.x

Russell, J. A. (1994). Is there universal recognition of emotion from facial expressions? A review of the cross-cultural studies. Psychological bulletin,115(1), 102. doi.org/10.1037/0033-2909.115.1.102

Samovar, L., Porter, R., McDaniel, E., \& Roy, C. (2015). Communication between cultures. Nelson Education.

Sarabi, H. (1975). Introduction to Arabian Societies. Arabic version. 
Schriefers, H., \& Vigliocco, G. (2015). Speech Production, Psychology of [Repr.]. In International Encyclopedia of the Social \& Behavioral Sciences (2nd ed) Vol. 23 (pp. 255-258). Elsevier.

Schwartz, S. H., Melech, G., Lehmann, A., Burgess, S., Harris, M., \& Owens, V. (2001). Extending the cross-cultural validity of the theory of basic human values with a different method of measurement. Journal of cross-cultural psychology, 32(5), 519542. doi: $10.1177 / 0022022101032005001$

Smith, E. R., \& Miller, F. D. (1978). Limits on perception of cognitive processes: A reply to Nisbett and Wilson. Psychological Review, 85(4), 355-362. doi:10.1037/0033295X.85.4.355

Sooniste, T., Granhag, P. A., Knieps, M., \& Vrij, A. (2013). True and false intentions: Asking about the past to detect lies about the future. Psychology, Crime \& Law, 19(8), 673-685. doi:10.1080/1068316X.2013.793333

Taylor, P., Larner, S., Conchie, S., \& Van der Zee, S. (2014). Cross-cultural deception detection. In P. A. Granhag, A. Vrij, \& B. Verschuere (Eds.), Deception detection: current challenges and cognitive approaches. (pp. 175-202). Chichester: Wiley Blackwell.

Vernham, Z., Vrij, A., Leal, S., Mann, S., Nahari, G. (2017). Applying the Verifiability Approach to the detection of deception in alibi witness situations. Manuscript submitted for publication.

Vrij, A. (2008). Detecting lies and deceit: Pitfalls and opportunities. John Wiley \& Sons. Vrij, A., Fisher, R., Mann, S., \& Leal, S. (2008). A cognitive load approach to lie detection. Journal of Investigative Psychology and Offender Profiling, 5(1-2), 3943. doi:10.1002/jip.82 
Vrij, A., Leal, S., Mann, S. A., \& Granhag, P. A. (2011). A comparison between lying about intentions and past activities: Verbal cues and detection accuracy. Applied Cognitive Psychology, 25(2), 212-218. doi:10.1002/acp.1665

Vrij, A., Granhag, P. A., Mann, S., \& Leal, S. (2011). Lying about flying: the first experiment to detect false intent. Pyschology, Crime \& Law, 17(7), 611-620. doi: $10.1080 / 10683160903418213$

Vrij, A., Nahari, G., Isitt, R., \& Leal, S. (2016). Using the verifiability lie detection approach in an insurance claim setting. Journal of Investigative Psychology and Offender Profiling, 13(3), 183-197. doi:10.1002/jip.1458

Warmelink, L., Vrij, A., Mann, S., Jundi, S., \& Granhag, P. A. (2012). The effect of question expectedness and experience on lying about intentions. Acta Psychologica, 141, 178-183. doi:10.1016/j.actpsy.2012.07.011

Wierzbicka, A. (1985). Different cultures, different languages, different speech acts: Polish vs. English. Journal of pragmatics, 9(2), 145-178. doi:10.1016/03782166(85)90023-2 
Table 1 Descriptive Statistics of Total Detail and Total Verifiable Details for Veracity and Region

\begin{tabular}{|c|c|c|c|c|c|c|c|c|c|c|c|c|c|c|}
\hline & $\begin{array}{c}\mathrm{TD} \\
\text { (sum) }\end{array}$ & $\begin{array}{l}\mathrm{TD} \\
(M)\end{array}$ & $\begin{array}{c}\mathrm{TD} \\
(S D)\end{array}$ & $\begin{array}{c}\text { TD } \\
\text { Mode }\end{array}$ & $\begin{array}{c}\text { TD } \\
\text { Range }\end{array}$ & $\begin{array}{c}\text { TD } \\
\text { Range } \\
(\min )\end{array}$ & $\begin{array}{c}\text { TD } \\
\text { Range } \\
\text { (Max) }\end{array}$ & TVD & $\begin{array}{l}\text { TVD } \\
(M)\end{array}$ & $\begin{array}{l}\text { TVD } \\
(S D)\end{array}$ & $\begin{array}{l}\text { TVD } \\
\text { Mode }\end{array}$ & $\begin{array}{l}\text { TVD } \\
\text { Range }\end{array}$ & $\begin{array}{l}\text { TVD } \\
\text { Range } \\
\text { (min) }\end{array}$ & $\begin{array}{l}\text { TVD } \\
\text { Range } \\
(\max )\end{array}$ \\
\hline Truth tellers Overall & 855 & 3.49 & 2.65 & 1 & 12 & 0 & 12 & 184 & .75 & 1.18 & 0 & 6 & 0 & 6 \\
\hline Liars Overall & 699 & 2.99 & 2.58 & 1 & 17 & 0 & 17 & 112 & .48 & .90 & 0 & 7 & 0 & 7 \\
\hline Europe Overall & 471 & 2.95 & 2.46 & 1 & 17 & 0 & 17 & 124 & .76 & 1.31 & 0 & 7 & 0 & 7 \\
\hline Africa Overall & 310 & 3.86 & 2.95 & 1 & 13 & 1 & 14 & 40 & .50 & .87 & 0 & 3 & 0 & 3 \\
\hline
\end{tabular}

VD. $=$ Verifiable Detail. TVD. $=$ Total Verifiable Detail 